\section{A CASE OF DYSTOCIA IN A MITHUN}

\section{(BOS FRONTALIS)}

\author{
I. Nath ${ }^{1}$, V.S.C. Bose ${ }^{2}$, S.K. Panda ${ }^{3}$, B.C. Das ${ }^{4}$, \\ R.K. Samantray ${ }^{5}$ and P.K. Roy ${ }^{5}$
}

${ }^{1}$ Assistant Professor, Surgery, ${ }^{2}$ Head, Department of Surgery, ${ }^{3}$ Assistant Professor, Pathology, ${ }^{4} \mathrm{Head}$, Department of Pathology, Orissa Veterinary College, Bhubaneshwar, Orissa 751003, India.

${ }^{5}$ V.A.S., Nandankanan Zoo, Bhubaneshwar, Orissa, India.

Dystocia or difficulty in parturition due to foetal oversize, abnormal presentation and maternal pelvic abnormalities require caesarian operation (Cattell \& Dobson, 1990). In their opinion $38 \%$ of the dystocias are due to foetal oversize. Abdul-Fadel and Gohar (1987) stated that elective caesarians are uncommon in farm animals and dystocia needs emergency caesarian section.

A Mithun (Bos frontalis) in Nandankanan Zoo, aged about 15 years and in its $8^{\text {th }}$ gestation showed symptoms of dystocia after its full term. Zoo authorities reported that the animal was showing symptoms for the past 36 hours with protruded fore limbs through the vulva (Fig.1). Attempts to extricate the foetus forcibly by rope traction by zoo doctors were not successful. Per-rectal examination revealed a large-sized foetus with deviated head and the uterus was very hard. Attempts to pass a hand for correction of the head position was not possible as there was no space between the foetus and the uterine wall. Hence it was decided to conduct a caesarian operation.

The animal was sedated with xylazine hydrochloride @ 0.1mg/ $\mathrm{kg}$ body weight. After routine preparation of the operation site, xylocaine $2 \%$ was infiltrated at left, lower flank ventro-oblique incision site of about $20 "$. On opening the abdomen the gravid uterine horn was palpated, which was very hard, large, extending from pelvic brim to almost near the diaphragm anteriorly compressing all the organs in the abdomen. Due to its abnormally large size the uterus could not be mobilized towards the incision site.

The gravid horn was covered all around with sterile gauze leaving the site of incision. An 18" long incision was made on the uterus starting anteriorly towards the body of the uterus. The foetus could not be removed due to its large size and the uterine wall tightly covered the foetus. Then it was decided to decompress the foetus by opening the abdominal cavity and puncturing the intestines to relieve the gas. After about 10 minutes the size of the foetus reduced slightly allowing a hand to pass and grasp the hind limbs one after the other. The foetus was slowly manipulated while two assistants pulled out the dead foetus holding the hind limbs. On verification, it was found that the uterus was already ruptured near the body on its medial aspect. The incised as well as the ruptured portion of the uterine horn was sutured in cushing fashion using chromic cat gut no.1. The abdominal cavity that had blood-tinged fluid was removed by soaking and squeezing with sterilized gauze cloth and flushing with saline repeatedly before it was closed.

Dicrysticins-S 20 lacs was given intramuscularly and $2 \mathrm{~L}$ of DNS was infused intravenously. The animal revived after two hours and walked slowly to its enclosure. After 24 hours, the zoo authorities reported that the animal had suddenly collapsed and died.

Post-mortem examination revealed congested and thickened peritoneum with about $5 \mathrm{~L}$ of blood-tinged fluid in the abdominal cavity. There was an abscess with caseated pus anterior to the aortic arch in the mediastinum. There was fibrinous pericarditis with firm adhesion to the surrounding organs and petechial haemorrhages on epicardium.

In the present case abnormally large size emphasematous changes after the death of the foetus and the deviated head did not facilitate correction and removal per vagina. Decompression of the foetus was required for manipulation, correction and extrication through the uterine incision. Prior rupture of the uterus might be responsible for peritonitis as observed in the post mortem examination. Post mortem findings suggest that death may be due to fibrinous pericarditis and toxaemia.

\section{Acknowledgement}

Authors are thankful to the Director, Nandankanan Zoo for the co-operation extended.

\section{References}

Abdul-Fadel, W.S. and H.M. Gohar (1987). Selection of an incision site for caesarotomy in protracted dystocias in ruminants. Journal of Egyptian Veterinary Medicine Association 47: 307-313.

Cattell, J.H. and H. Dobson (1990). A survey of caesarian operations on cattle in general veterinary practice. Veterinary Records 127: 395399.

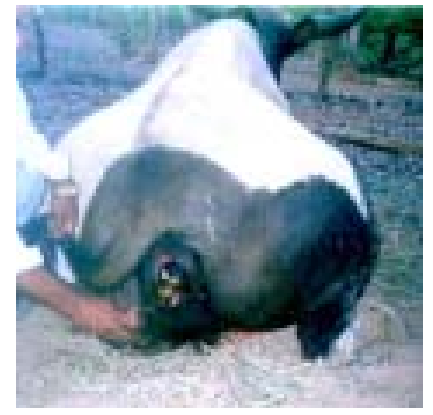

Figure 1. Photograph showing protruded forelimbs of the foetus

Received 1 July 2002

Finally accepted 6 December 2002 